\title{
Oblique Columnar Assemblies of Polycatenar Molecules via Click Chemistry
}

\author{
Jin-Woo Choi, Ji-Hye Han, Mee-Hi Ryu, and Byoung-Ki Cho* \\ Department of Chemistry and Institute of Nanosensor and Biotechnology, Dankook University, \\ Gyeonggi-Do 448-701, Korea.*E-mail: chobk@dankook.ac.kr \\ Received September 16, 2010, Accepted December 6, 2010
}

Key Words : Polycatenar, Columnar, Click reaction, 1,2,3-Triazole, Liquid crystal

Polycatenar liquid crystals (LCs) are an interesting class of building blocks because their self-assembling behavior shares characteristics of calamitic and discotic LCs. ${ }^{1}$ Depending on the number of peripheral chains connected to the central rigid rod, polycatenar LCs self-organize into lamellar (like calamitic LC)/ or columnar (like discotic LC) structures in the bulk states. In addition, 2-D packing morphologies (mostly hexagonal or rectangular) of their supramolecular columns were reported to be strongly dependent upon the shape of the column cross-section. Due to the diverse assembling behavior, this polycatenar system recently becomes more popular when devising functional soft materials.

Click chemistry has received explosive attention organic and polymeric materials, because it can provide a very efficient synthetic pathway for designing self-assembling soft materials. ${ }^{2}$ In particular, this click chemistry has been extensively utilized as a coupling reaction between alkyne and azide to simply combine organic building units into more complex architectures. ${ }^{3}$ Meanwhile, 1,2,3-triazole ring formed by the click chemistry, is an aromatic heterocycle, resulting in its high chemical and thermal stabilities. Thus, a linear conjugation to other aromatic groups possibly enhances molecular anisotropy, which is a prerequisite for achieving LC materials. In this regard, the click chemistry could be a promising synthetic candidate for the preparation of mesogenic groups. Despite this synthetic versatility, so far only a few LC examples using click chemist have been reported. Most of them were calamitic mesogens ${ }^{4}$ exhibiting nematic or smectic mesophases, and only a few of discotic $\mathrm{LCs}^{5}$ were reported.

In this context, it would be interesting to use the click chemistry for the preparation of polycatenar LC molecules. To the best of our knowledge, to date no polycatenar molecule using the click chemistry has been synthesized. The designed molecular structure is shown in Scheme 1. The rigid rod consists of two 1,2,3-triazoles which are connected at 1,4-positions of the

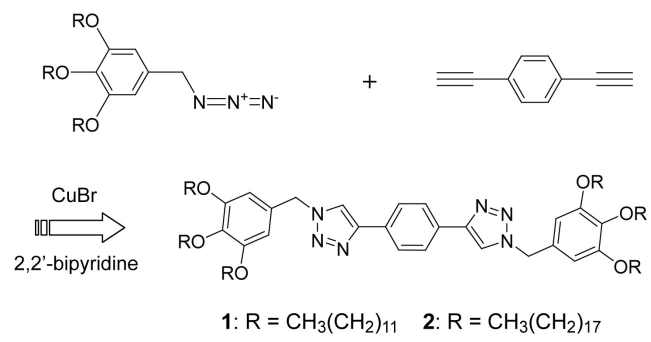

Scheme 1. Preparation of polycatenar compounds 1 and 2 through a click reaction central benzene ring. This structure was easily accomplished by a click reaction (using $\mathrm{Cu}(\mathrm{I}) \mathrm{Br}$ and 2,2'-bipyridine as catalysts) between azide-terminated compounds and alkyne precursor. ${ }^{5 \mathrm{a}, 6}$

The final compounds were characterized by ${ }^{1} \mathrm{H}$ - and ${ }^{13} \mathrm{C}-\mathrm{NMR}$ spectroscopies, elemental analysis, and gel permeation chromatography. As a representative example, the ${ }^{1} \mathrm{H}-\mathrm{NMR}$ spectrum of compound $\mathbf{1}$ displayed a signal for the protons in the triazoles at $7.68 \mathrm{ppm}$, and other aromatic protons and benzyl methylene protons could be assigned as might be expected (Figure S1(a)). In addition, eight distinct carbon signals appeared in the aromatic region of the ${ }^{13} \mathrm{C}$-NMR spectrum of 1 (Figure $\mathrm{S} 1(\mathrm{~b})$ ), which corroborates the formation of the designed aromatic structure. Both polycatenar molecules showed narrow polydispersities $\left(\mathrm{M}_{\mathrm{w}} / \mathrm{M}_{\mathrm{n}}\right)$ of 1.01 in gel permeation chromatography (GPC) data, indicative of high purities (Figure S2).

The thermal properties of $\mathbf{1}$ and $\mathbf{2}$ were characterized by differential scanning calorimetry (DSC) (Figure S3). Upon heating of 1 with dodecyl peripheries, a crystalline phase went into a LC phase at $70.2^{\circ} \mathrm{C}$, which in turn underwent isotropization at $117.4{ }^{\circ} \mathrm{C}$. Likewise, on the heating compound 2 with octadecyl chains displayed two endothermic peaks at $91.8^{\circ} \mathrm{C}$ and $96.1{ }^{\circ} \mathrm{C}$, corresponding to the melting and isotropization transitions, respectively. Also, on the cooling, the LC phase existed over an extended temperature range from $74.5^{\circ} \mathrm{C}$ to $88.4{ }^{\circ} \mathrm{C}$.

To identify LC phases, it is often useful to examine their optical textures using a polarized optical microscopy (POM). ${ }^{7}$ The LC phases of $\mathbf{1}$ and $\mathbf{2}$ were analyzed using a temperature-variable POM. Similar textures in both LC phases were observed, and a representative POM image was presented in Figure 1(a). On slow cooling from the isotropic liquid of 2, a flower-like texture with Maltese crosses appears, which suggests a columnar

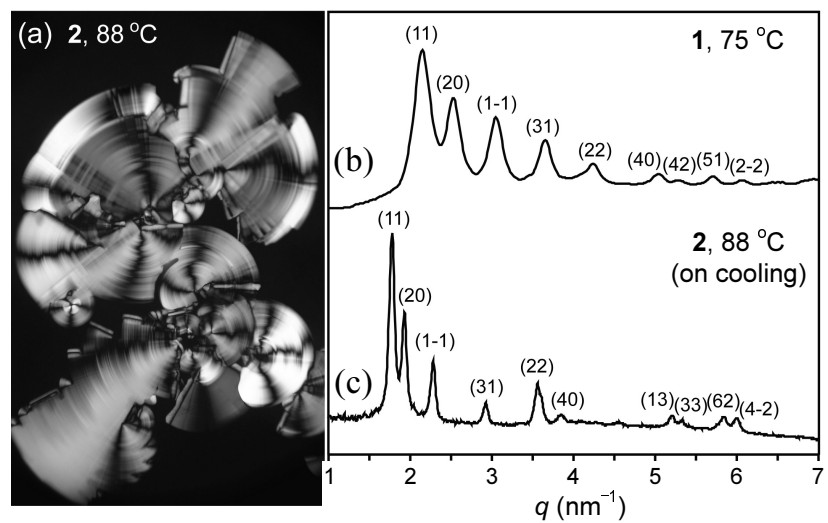

Figure 1. (a) Polarized optical microscopy texture of 2 taken at $88^{\circ} \mathrm{C}$ on the cooling, and the SAXS spectra of (b) 1 at $75^{\circ} \mathrm{C}$, and (c) 2 at $88^{\circ} \mathrm{C}$. 


\section{LC phase. $^{8}$}

More detailed information of the LC structure could be obtained by performing small and wide angle X-ray scattering (SAXS and WAXS) experiments. In their LC phase, both compounds displayed a considerable number of Bragg diffraction peaks in the small angle region, together with a diffuse halo in the wide angle region (Figure 1 and S4). Through fitting to various structural models, the patterns were in good agreement with a 2-dimensional oblique columnar structure $\left(\mathrm{Col}_{\mathrm{o}}\right)$ with a space group of $P 1$ (See Table S1 and S2). As illustrated in Figure 2(a), the unit cell consisting of two columns is distorted in comparison with conventional 2-dimensional hexagonal columnar. To date, most of polycatenar molecules were reported to selforganize into highly symmetric columnar structures such as 2-dimensional hexagonal or rectangular ones. On the other hand, this type of oblique columnar assembly is still very unusual, although only a few examples were reported. ${ }^{1,9}$ The lattice parameters a, b, and $\gamma$ were estimated to be $5.47 \mathrm{~nm}(6.82 \mathrm{~nm}), 2.98$ $\mathrm{nm}(3.65 \mathrm{~nm})$, and $66.1^{\circ}\left(73.1^{\circ}\right)$ for compound 1 (2) (Figure 2(a)).

Next, it is possible to calculate the number of molecules $(N$, $N$ is integer) consisting of a columnar slice by dividing the cross-sectional volume $\left(\mathrm{V}_{\mathrm{c}}\right)$ of each column by the molecular volume $\left(\mathrm{V}_{\mathrm{m}}\right)$. For this, one may simply think that the related equation is $\mathrm{V}_{\mathrm{c}}=\mathrm{a} \times \mathrm{b} \times \sin \gamma \times 4.5 \AA$ where $4.5 \AA$ is the column stratum from a diffuse halo in the WAXS data. ${ }^{10}$ However, the calculation using this equation could not afford to an integer $N$. Therefore, the tilt angle $(\alpha)$ of the columnar slice with respect to the normal to the columnar axis should be taken into account (Figure 2(b)). ${ }^{11}$ Otherwise the calculated $\mathrm{V}_{\mathrm{c}}$ would be significantly smaller than the real value. Finally, the $\mathrm{V}_{\mathrm{c}}$ should be modified into the following equation; $\mathrm{V}_{\mathrm{c}}=(\mathrm{a} \times \mathrm{b} \times \sin \gamma \times 4.5 \AA) /$ $\cos \alpha$. As far as the molecular volume $\left(\mathrm{V}_{\mathrm{m}}\right)$ was concerned, the densities were assumed to be $1.0 \mathrm{~g} / \mathrm{cm}^{3} .{ }^{12}$ The resulting calculations suggested that $N=2$ is the most plausible for both $\mathbf{1}$ and 2. When $N>2$, the reduced molecular length (i.e., fully stretched molecular length $\times \cos \alpha$ ) is even shorter than the smaller lattice parameter $b$, which cannot fill the 2-D unit cell. Therefore, $N>2$ can be ruled out. At $N=2$, the corresponding $\alpha$ values were determined to be $48^{\circ}$ and $37^{\circ}$ for 1 and 2 , respectively. As compared to $\mathbf{1}$, the smaller $\alpha$ of 2 with longer octadecyl peripheries might be due to the fact that the longer octadecyl chains occupy the lateral regions of rod segments,
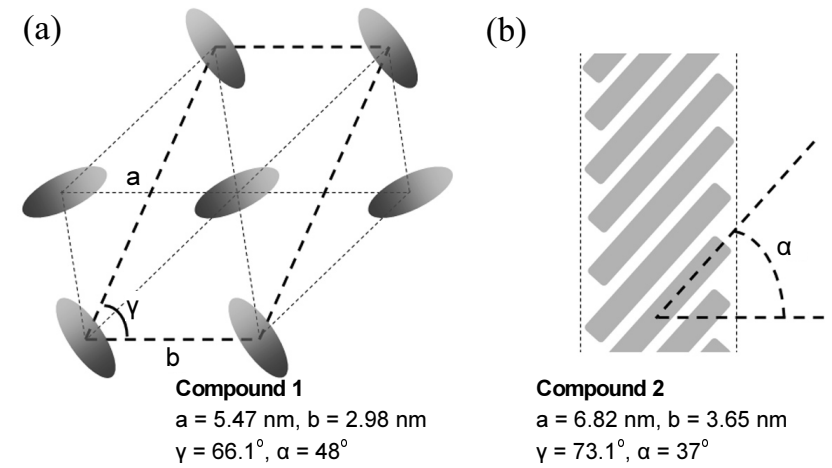

Figure 2. Schematic illustrations of (a) molecular organization in the $\mathrm{Col}_{\mathrm{O}} \mathrm{LC}$ phase, and (b) the molecular tilt angle with respect to the normal to the columnar axis. For reasons of clarity, alkyl chains are omitted in (a) and (b). In (a), the darker and brighter regions indicate the lower and upper parts of tilt rods, respectively. leading to a less elliptical cross-section. This could be understood by considering that a completely circular columnar crosssection is expected to have $\alpha=$ zero.

In summary, polycatenar molecules $\mathbf{1}$ and $\mathbf{2}$ with dodecyl and octadecyl peripheries, respectively, were synthesized for the first time with the aid of an efficient copper-catalyzed click reaction. Both polycatenar molecules exhibited LC phases on heating and cooling scans. SAXS analysis indicated that these LC phases were revealed as unusual 2-D oblique columnar structures. The calculations based upon the SAXS data and molecular volumes suggested that the elliptical cross-sections stack on top of each other with a certain tilt angle with respect to the normal to the columnar axis.

Acknowledgments. The present research was conducted by the research fund of Dankook university in 2010. We acknowledge Pohang Accelerator Laboratory (Beamline 10C1), Korea.

Supporting Information. The supporting Information is available on request from the corresponding author (E-mail: chobk@, dankook.ac.kr).

\section{References}

1. (a) Nguyen, H.-T.; Destrade, C.; Malthête, J. Adv. Mater. 1997, 9, 375. (b) Gharbia, M.; Gharbi, A.; Nguyen, H. T.; Malthête, J. Curr. Opin. Colloid Interface Sci. 2002, 7, 312.

2. Rostovtsev, V. V.; Green, L. G.; Fokin, V. V.; Sharpless, K. B. Angew. Chem., Int. Ed. 2002, 41, 2596.

3. (a) Fournier, D.; Hoogenboom, R.; Schubert, U. S. Chem. Soc. Rev. 2007, 36, 1369. (b) Hua, C.; Peng, S.-M.; Dong, C.-M. Macromolecules 2008, 41, 6686. (c) Lin, W.; Fu, Q.; Zhang, Y.; Huang, J. Macromolecules 2008, 41, 4127. (d) Franc, G.; Kakkar, A. Chem. Commun. 2008, 5267. (e) Lee, J. W.; Kim, B.-K. Bull. Korean Chem. Soc. 2005, 26, 658.

4. (a) Gallardo, H.; Ely, F.; Bortoluzzi, A. J.; Conte, G. Liq. Cryst. 2005, 32, 667. (b) Cui, Z.; Zhang, Y.; He, S. Colloid Polym. Sci. 2008, 286, 1553. (c) Xia, Y.; Verduzco, R.; Grubbs, R. H.; Kornfield, J. A. J. Am. Chem. Soc. 2008, 130, 1735. (d) Saravanan, C.; Senthil, S.; Kannan, P. J. Polym. Sci., Part A: Polym. Chem. 2008, 46, 7843. (e) Srividhya, D.; Manjunathan, S.; Thirumaran, S.; Saravanan, C; Senthil, S. J. Mol. Struct. 2009, 927, 7.

5. (a) Ryu, M.-H.; Choi, J.-W.; Cho, B.-K. J. Mater. Chem. 2010, 20, 1806. (b) Choi, J.-W.; Ryu, M.-H.; Lee, E.; Cho, B.-K. Chem. Eur. J. 2010, 16, 9006. (c) Beltrán, E.; Serrano, J. L.; Sierra, T.; Giménez, R. Org. Lett. 2010, 12, 1404.

6. Mespouille, L.; Vachaudez, M.; Suriano, F.; Gerbaux, P.; Coulembier, O.; Degee, P.; Flammang, R.; Dubois, P. Macromol. Rapid Commun. 2007, 28, 2151.

7. (a) Han, T. H.; Kim, J.; Park, J. S.; Park, C. B.; Ihee, H.; Kim, S. O. Adv. Mater. 2007, 19, 3924. (b) Park, J. S.; Han, T. H.; Oh, J. K.; Kim, S. O. Macromol. Chem. Phys. 2009, 210, 1283.

8. Serrano, J. L.; Sierra, T. Coord. Chem. Rev. 2003, 242, 73.

9. Raïs, K.; Daoud, M.; Gharbia, M.; Gharbi, A.; Nguyen, H. T. ChemPhysChem. 2001, 2, 45.

10. Percec, V.; Ahn, C.-H.; Bera, T. K.; Ungar, G.; Yeardley, D. J. P. Chem. Eur. J. 1999, 5, 1070.

11. (a) Donnio, B.; Heinrich, B.; Allouchi, H.; Kain, J.; Diele, S.; Guillon, D.; Bruce, D. W. J. Am. Chem. Soc. 2004, 126, 15258. (b) Yasuda, T.; Kishimoto, K.; Kato, T. Chem. Commun. 2006, 3399. (c) Würthner, F.; Thalacker, C.; Diele, S.; Tschierske, C. Chem. Eur. J. 2001, 7, 2245. (d) Ribeiro, A. C.; Heinrich, B.; Cruz, C.; Nguyen, H. T.; Diele, S.; Schröder, M. W.; Guillon, D. Eur. Phys. J. E 2003, 10, 143 .

12. (a) Yasuda, T.; Ooi, H.; Morita, J.; Akama, Y.; Minoura, K.; Funahashi, M.; Shimomura, T.; Kato, T. Adv. Funct. Mater. 2009, 19, 411. (b) Seo, J.; Kim, S.; Gihm, S. H.; Park, C. R.; Park, S. Y. J. Mater. Chem. 2007, 17, 5052. 